\title{
Fundamentos de neurociência presentes na inclusão escolar: vivências docentes
}

Luciane Grecilo da Silva* Elena Maria Billig Mello**

\section{Resumo}

Esta pesquisa-ação objetivou investigar estratégias de ensino-aprendizagem, com suporte na Neurociência, com vista à acessibilidade pedagógica de alunos incluídos, à inovação pedagógica e ao respeito à diversidade, em turma regular, no Ensino Fundamental, de uma escola pública estadual. Relatos da prática docente no diário de itinerância digital, fotografias e vídeos, foram analisados e registrados em momentos de pré, durante e pós-intervenções com estratégicas pedagógicas. Após diagnóstico inicial e verificação de problemáticas no processo ensino-aprendizagem, cinco estratégias pedagógicas com base na Neurociência foram planejadas, aplicadas e analisadas, desdobrando-se em cinco categorias norteadoras: estética, emoçôes, inclusão, autonomia e Neuroeducação. A proposta de intervenção embasou-se na metodologia dialética. Os resultados evidenciaram a necessidade da mobilização e sensibilização do grupo como um todo, assim como de resgate da autonomia, autoestima e participação dos alunos incluídos. Proporcionou-se contexto flexibilizado, com respeito aos ritmos, às capacidades e às condições neurofisiológicas, observando relaçôes entre o científico e o educacional. Com a percepção de que existem cérebros diferentes, faz-se necessário olhar e valorizar propostas pedagógicas que estejam atentas à acessibilidade pedagógica para dessa forma tornarmos a inclusão uma realidade.

Palavras-chave: Neurociência; Inclusão; Acessibilidade pedagógica; Ensino fundamental.

\footnotetext{
* Mestranda em Ensino pela Universidade Federal do Pampa, Rio Grande do Sul, Brasil.
}

** Professora doutora da Universidade Federal do Pampa, Rio Grande do Sul, Brasil. 


\section{Foundations of neuroscience present in school inclusion: teaching living}

\section{Abstract}

This research-action aimed at investigating teaching-learning strategies, with support in neuroscience, with a view to the pedagogical accessibility of included pupils, pedagogical innovation and respect for diversity, in regular classes, in elementary school, of a state public schools. Reports of the teaching practice in the Itinerant Digital Diary, photographs and videos, were analyzed and recorded in moments of pre, during and post interventions with pedagogical strategics. After initial diagnosis and problem verification in the teaching-learning process, five pedagogical strategies based on neuroscience were planned, applied and analyzed, unfolding in five categories guiding: Aesthetics, emotions, inclusion, autonomy and Neuroeducation. The proposal for intervention was based in the dialectic methodology. The results showed the need for the mobilization and awareness of the group as a whole, as well as to rescue the autonomy, self-esteem and participation of the included pupils. A flexible context has been provided, with respect to rhythms, capacities and neurophysiological conditions, observing relationships between scientific and educational. With the perception that there are different brains, it is necessary to look and value pedagogical proposals that are attentive to the pedagogical accessibility so that we make the inclusion a reality.

Keywords: Neuroscience; Inclusion; Pedagogical accessibility; Elementary school.

\section{Introdução}

$\mathrm{Na}$ atualidade percebemos que a aproximação entre Neurociência e Educação tem recebido maior atençáo, devido sua popularização no meio acadêmico-profissional. Nesse sentido, o presente artigo apresenta resultados da aplicação de estratégias de ensino-aprendizagem, com suporte na Neurociência, com vistas à acessibilidade pedagógica em turma regular do Ensino Fundamental com alunos incluídos, em uma escola pública, na perspectiva da inovaçấo pedagógica e do respeito à diversidade.

Tokuhama-Espinosa (2008) considera Neuroeducação uma nova área interdisciplinar com a finalidade de abordar o conhecimento e a inteligência, integrando três áreas: a Psicologia, a Educação e as Neurociências. Nesse sentido encontramos também a colaboração de Zaro et al. (2010), que apontam a Neuroeducação a integração entre as duas áreas - Neurociência e Educação - e as contribuiçôes para o processo de aprendizagem e para a melhoria da prática educativa.

Cosenza e Guerra (2011, p. 142) esclarecem que "as Neurociências estudam os neurônios e suas moléculas constituintes, os órgãos do sistema nervoso e suas funçôes específicas, e também as funçôes cognitivas e o comportamento que são resultantes da atividade dessas estruturas". Complementam expressando ser o cérebro responsável pela forma de processar a informação, armazenar e selecionar o conhecimento, e destacam que para que isso faz-se necessário compreender seu funcionamento e estratégias para melhorar seu desenvolvimento. 
Os referidos autores ressaltam processos neurocientíficos fundamentais no processo ensino-aprendizagem com destaque para a organização do sistema nervoso, seu desenvolvimento e neuroplasticidade: assim como a atenção, a memória, a inteligência, as emoçôes e suas implicaçôes na aprendizagem, dentre outros fatores. Segundo os autores, "o trabalho do educador pode ser mais significativo e eficiente quando ele conhece o funcionamento cerebral” (COSENZA e GUERRA, 2011, p. 143).

Esses autores nos ajudam a entender os momentos em sala de aula com alunos incluídos, pois esclarecem que é necessário estar atento ao "funcionamento do sistema nervoso em aprendizes com cérebros diferentes, como autistas, crianças com deficiência mental, síndrome de Down, entre outros". Acrescentam que considerar o funcionamento cerebral distinto na proposição de estratégias pedagógicas é "condição imprescindível para tornar a educação, inclusive de crianças e adolescentes com necessidades educacionais especiais, uma realidade" (Idem, 2011, p. 145).

Surge, então, no contexto desta pesquisa, uma linha de estudo que propõe olhar à inclusão. Baptista (2015) nos traz consideraçóes relevantes referentes à intensificação de intervenções pedagógicas, visando oportunizar às pessoas com deficiências diferentes modos de viver na escola. Acrescentamos ideias relacionadas à acessibilidade no sentido destacado por Veiga (2015, p. 2) em que os princípios curriculares e de formação de profissionais de educação, especialmente de docentes, relacionam-se aos princípios da acessibilidade pedagógica, que: "Refere-se à ausência de barreiras nas metodologias e técnicas de estudo. Está relacionado diretamente à concepção subjacente à atuação docente: a forma como os professores concebem conhecimento, aprendizagem, avaliação"; complementada pela acessibilidade atitudinal, que, segundo a autora, "diz respeito à percepção do outro, sem preconceitos, estigmas, estereótipos e discriminaçôes”. (Idem).

Ao referirmo-nos à inclusão, optamos pela proposta de flexibilização curricular ao invés da ideia de adaptação curricular que, segundo Garcia (2007), essa organiza as atividades educacionais de acordo com diagnósticos e prognósticos clínicos sobre o desenvolvimento de alunos incluídos. A referida autora $(2007$, p. 13) destaca estratégias de flexibilidade curricular relacionadas à inclusão educacional centradas na perspectiva de "diversificar as opçóes de aprendizagem, promover ajuda entre as crianças, oferecer suporte para as dificuldades apresentadas pelos alunos e desenvolver relacionamentos mais próximos com as famílias e a comunidade". Para ela é através disso que se faz uma conexão entre currículo flexível e o trabalho pedagógico inclusivo.

Apresentamos, a seguir, o percurso metodológico da pesquisa, os resultados e discussão acerca das estratégias, e encerramos com (in)conclusões encontradas durante este estudo.

\section{Percurso metodológico}

A pesquisa-ação denota a presente investigaçáo, com abordagem qualitativa, a partir dos estudos de Thiollent (2011) e de Thiollent e Colette (2014, p. 208), que expressam que essa pesquisa se destina "mais ainda, nas modalidades de formação 
destinadas a grupos específicos, levando em conta aspectos como: classe social, etnia, gênero, profissóes, trabalho, campo/cidade, níveis de renda, exclusão, faixas etárias, saúde, meio ambiente etc." Com isso, colocam a importância de "trazê-la como proposta de trabalho pedagógico completo, interagindo com o currículo em sala de aula"' (Idem).

Realizamos intervençôes junto a um grupo de 25 alunos na faixa etária entre 10 e 16 anos, com foco em dois alunos incluídos em um $5^{\circ}$ ano regular de uma escola pública do município de Uruguaiana/RS.

Para a coleta de dados utilizamos as anotações do diário de itinerância (BARBIER apud ALMEIDA, 2012) em formato digital, resultantes de observaçóes e reflexôes na implementação de estratégias pedagógicas com base em Neurociência, bem como dos avanços e limitaçóes dos discentes incluídos, entre outros aspectos.

Após diagnóstico inicial, cinco estratégias pedagógicas com base na Neurociência foram planejadas, aplicadas e analisadas, desdobrando-se em cinco categorias norteadoras: estética, emoções, inclusão, autonomia e Neuroeducação.

O planejamento e a aplicação das estratégias, foram realizados a partir de momentos pedagógicos da tríade dialética de Vasconcellos (2005): síncrese (mobilização do grupo), análise (envolvimento do grupo), síntese (do que se re-construiu de conhecimento), com foco nas expressôes oral, corporal, artística, estética, e nos conhecimentos da Neurociência. As estratégias foram aplicadas em ambiente acolhedor, com espaço para trocas em prol da construçấo coletiva e ampliação de conhecimentos. As atividades foram aplicadas em 22 dias letivos, de forma lúdica, com modificaçôes no ambiente de sala de aula, às vezes em círculos, formato $\mathrm{U}$, duplas, trios ou grupos maiores, possibilitando integração e interação.

$\mathrm{Na}$ análise dos resultados das estratégias pedagógicas, a reflexão sobre a ação esteve voltada à acessibilidade pedagógica e à neurociência aplicada à educação, a partir das cinco categorias já referidas.

\section{Resultados e discussão}

No diagnóstico do grupo, observamos idade, áreas de estudo preferidas, interesses, estilos de aprendizagem dominantes, dificuldades de aprendizagem e relacionamento. Os alunos demonstraram respeito e disciplina, sendo conscientes frente à inclusão, mas necessitam direcionamento quanto ao acolhimento dos alunos incluídos. Dentre os alunos incluídos, um apresenta Síndrome de Down e outro Retardo Mental Leve.

A escola dispóe de uma Sala de Recursos Multifuncional para Atendimento Educacional Especializado (AEE) onde alunos são atendidos uma vez por semana em turno inverso, por uma profissional que forneceu relatórios descritivos (2016) dos dois alunos incluídos. Nâo há monitora em sala de aula para acompanhar individualmente esses alunos, conforme prevê a legislação. 
A aluna X, 14 anos, está registrada com Síndrome de Down, considerada calma, tímida; introspectiva e com dificuldades para entrosamento com colegas e professores da escola. $\mathrm{Na}$ época apresentava dificuldades acentuadas em: linguagem oral e escrita; reconhecimento e funçôes dos órgãos dos sentidos, equilíbrio e lateralidade, coordenação ampla e fina, percepções sensoriais e temporais, raciocínio lógico-matemático. Foram destacadas potencialidades: reconhece algumas partes do corpo, desenvolve com êxito atividades de coordenação viso-motora, percepção espacial, análise, síntese e figura-fundo e no raciocínio-lógico atividades de correspondência.

Referente ao aluno Y, 16 anos, está registrado sob a descrição de Encefalopatia crônica, que implica no desenvolvimento neuromotor, retardo. Considerado calmo, tranquilo, que fala pouco. Dentre suas potencialidades: identificava as partes do corpo; apresentava coordenação motora ampla boa, percepçôes sensoriais, análise, síntese e figura-fundo; conseguia escrever em caixa alta (letra de forma); no raciocínio lógico-matemático realizava atividades de classificação e inclusão. Algumas dificuldades apresentadas: relacionamento com os colegas, idade cronológica diferente dos alunos da sala regular, reconhecimento dos órgãos dos sentidos; lateralidade, organização e expressão do corpo humano; coordenação motora fina, desenhar e pintar; linguagem oral e escrita (fala com supressão e ou troca de letras) e no raciocínio lógico-matemático. Foram planejadas e implementadas cinco estratégias pedagógicas com participação de todos os alunos. A análise da implementação de cada estratégia destacou comportamento e possíveis evoluçóes da aprendizagem dos alunos incluídos em cada momento previsto na tríade dialética (síncrese, análise e síntese), observando aspectos ligados à acessibilidade pedagógica e à neurociência.

Observamos a aproximação entre educação e os fundamentos da Neurociência, com destaque para a presença do princípio da flexibilização curricular (GARCIA, 2007), nas açôes mobilizadas com os alunos incluídos, como veremos na Tabela 1 e no Quadro 1.

A Tabela 1 apresenta as cinco estratégias pedagógicas, com diferentes enfoques, desenvolvendo expressão oral, escrita e artística, interação, integração, comunicação, diálogo, senso crítico, autoconhecimento, observação do meio/contexto, emoçôes, participação. 
Tabela 1 - Estratégias pedagógicas e seus enfoques

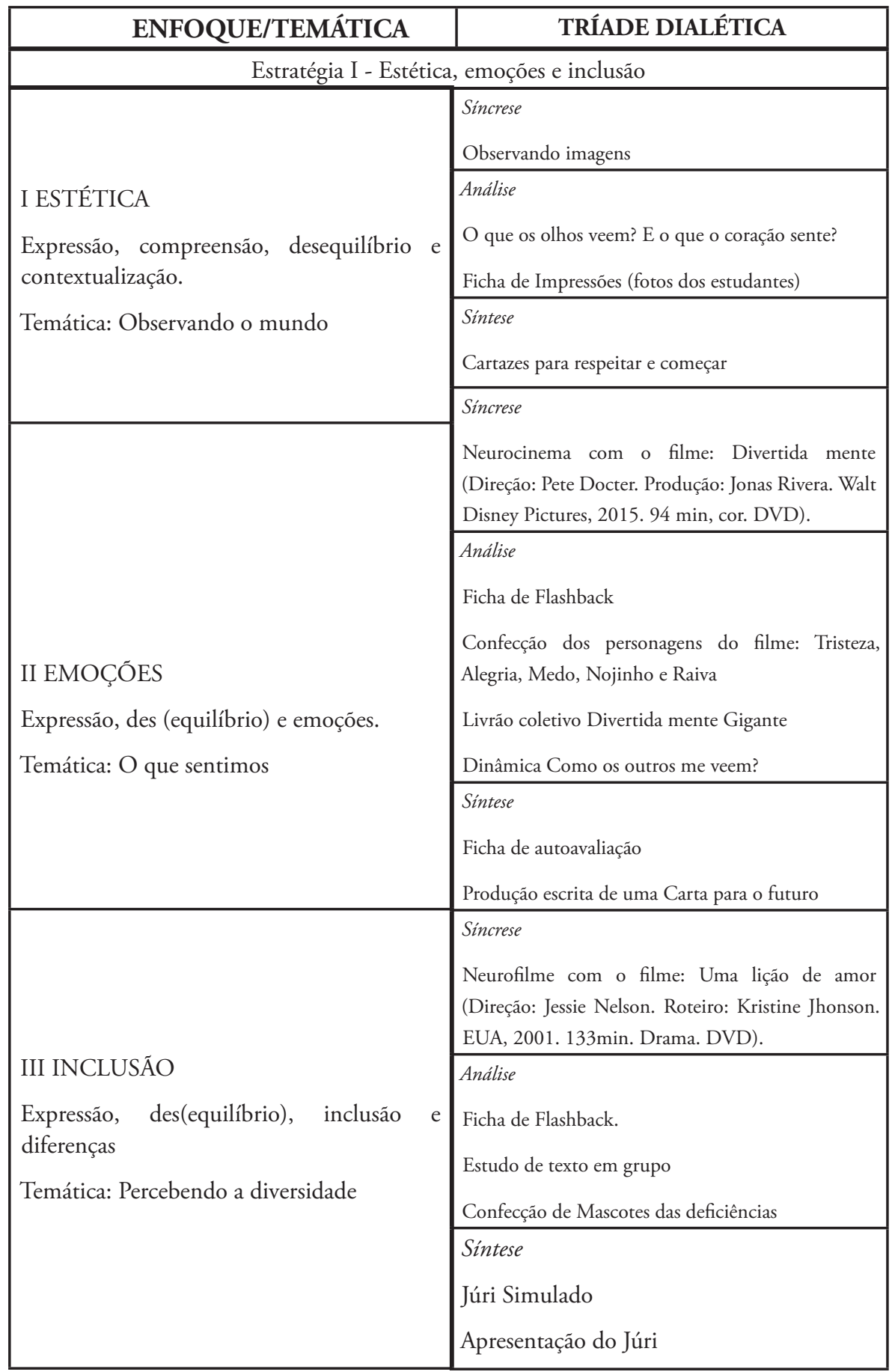




\begin{tabular}{|c|c|}
\hline \multicolumn{2}{|c|}{ Estratégia II- Sentidos } \\
\hline \multirow{3}{*}{$\begin{array}{l}\text { I MULTISSENSORIAL } \\
\text { Sensaçóes, diferentes formas de perceber o } \\
\text { mundo } \\
\text { Temática: Aprendo porque experimento }\end{array}$} & $\begin{array}{l}\text { Sincrese } \\
\text { Circuito Multissensorial }\end{array}$ \\
\hline & $\begin{array}{l}\text { Análise } \\
\text { Circuito Multissensorial }\end{array}$ \\
\hline & $\begin{array}{l}\text { Sintese } \\
\text { Debate: Como sentimos o mundo }\end{array}$ \\
\hline \multirow{3}{*}{$\begin{array}{l}\text { II SENTIDOS E EXPERIMENTAÇÓES } \\
\text { Sentidos, percepções, compreensão de } \\
\text { conceitos } \\
\text { Temática: Aprendo experimentando }\end{array}$} & $\begin{array}{l}\text { Sincrese } \\
\text { Experimentaçôes com material concreto } \\
\text { Anelina comestível } \\
\text { Imagens de confusão visual } \\
\mathrm{CD} \text { com diferentes barulhos/ou gravados no } \\
\text { computador } \\
\text { Passeio pela escola }\end{array}$ \\
\hline & $\begin{array}{l}\text { Análise } \\
\text { Estudo de Textos } \\
\text { Livro: Os sentidos explicados para crianças de } 7 \text { a } \\
9 \text { anos } \\
\text { Trabalhos em grupo } \\
\text { Resumo sobre cada sentido } \\
\text { Confecção de cartazes e apresentaçóes dos Mapas } \\
\text { dos Sentidos }\end{array}$ \\
\hline & $\begin{array}{l}\text { Sintese } \\
\text { Ficha Registro dos Sentidos }\end{array}$ \\
\hline \multirow{3}{*}{$\begin{array}{l}\text { III SENTIDOS E PERCEPÇÓES } \\
\text { Sentidos, percepções, compreensão e senso } \\
\text { crítico } \\
\text { Temática: Aprendo participando }\end{array}$} & $\begin{array}{l}\text { Sincrese } \\
\text { Jogo Batalha Naval } \\
\text { Brincando com assuntos pessoais, observação das } \\
\text { regras. }\end{array}$ \\
\hline & $\begin{array}{l}\text { Análise } \\
\text { Estudo dos Livros: Coleção Memórias de um } \\
\text { Neurônio Lembrador } \\
\text { Encenaçōes/Horas do Conto em grupos }\end{array}$ \\
\hline & $\begin{array}{l}\text { Sintese } \\
\text { Atividade Quadro-resumo O que } \\
\text { entendemos sobre o Sistema Nervoso }\end{array}$ \\
\hline
\end{tabular}




\begin{tabular}{|c|c|}
\hline \multicolumn{2}{|c|}{ Estratégia III- Sistema Nervoso e Neurociência } \\
\hline \multirow{8}{*}{$\begin{array}{l}\text { I NEUROCIÊNCIA } \\
\text { Sistema Nervoso. Temática: Meu Sistema é } \\
\text { Nervoso }\end{array}$} & Sincrese \\
\hline & Vídeo informativo \\
\hline & Cérebro máquina de aprender \\
\hline & Análise \\
\hline & Estudo dos Livros: Coleção Memórias de um \\
\hline & Neurônio Lembrador \\
\hline & Encenaçōes/Horas do Conto em grupos \\
\hline & Sintese \\
\hline \multirow{10}{*}{$\begin{array}{l}\text { II MAPEANDO O SISTEMA NERVOSO } \\
\text { Sistema Nervoso } \\
\text { Temática: Mapeando o Sistema Nervoso }\end{array}$} & $\begin{array}{l}\text { Atividade Quadro-resumo O que entendemos sobre } \\
\text { o Sistema Nervoso }\end{array}$ \\
\hline & Sincrese \\
\hline & Registro das pistas e suas respostas sobre Sistema \\
\hline & Nervoso \\
\hline & Jogo dos erros (construçáo de seu próprio exemplo) \\
\hline & Análise \\
\hline & Registro das pistas e suas respostas sobre Sistema \\
\hline & Jogo dos erros (construçáo de seu próprio exemplo) \\
\hline & Sintese \\
\hline & $\begin{array}{l}\text { NeuroQuiz com as perguntas elaboradas em grupo } \\
\text { sobre o Sistema Nervoso }\end{array}$ \\
\hline \multicolumn{2}{|c|}{ Estratégia IV- Memória } \\
\hline \multirow{6}{*}{$\begin{array}{l}\text { I TIPOS DE MEMÓRIA } \\
\text { Tipos de memória } \\
\text { Temática: Memória de elefante }\end{array}$} & Sincrese \\
\hline & Dinâmica Memória e Partilha \\
\hline & Análise \\
\hline & Estudo textual: Tipos de Memória \\
\hline & \\
\hline & Jogos da Memória \\
\hline
\end{tabular}




\begin{tabular}{|c|c|}
\hline \multirow{4}{*}{$\begin{array}{l}\text { II REGISTRO IMAGÉTICO/MEMÓRIA } \\
\text { Temática: Memorizo o que vivo }\end{array}$} & $\begin{array}{l}\text { Sincrese } \\
\text { Fotos de episódios vividos }\end{array}$ \\
\hline & Análise \\
\hline & $\begin{array}{l}\text { Atividades de descrição escrita e oral cruzadas dos } \\
\text { episódios }\end{array}$ \\
\hline & $\begin{array}{l}\text { Sintese } \\
\text { Mural: Nossos Registros Imagéticos }\end{array}$ \\
\hline \multicolumn{2}{|c|}{ Estratégia V-Área da mente, habilidades e competências } \\
\hline \multirow{3}{*}{$\begin{array}{l}\text { I PERCEPÇÃO CEREBRAL } \\
\text { Funções, características e partes cerebrais } \\
\text { fundamentais, lobos, hemisférios, } \\
\text { habilidades e competências } \\
\text { Temática: Quebrando a cabeça }\end{array}$} & $\begin{array}{l}\text { Sincrese } \\
\text { Montagem de um quebra-cabeça com Lobos } \\
\text { Cerebrais em EVA }\end{array}$ \\
\hline & $\begin{array}{l}\text { Análise } \\
\text { Jogo dos erros } \\
\text { Estudo de material impresso com localização e } \\
\text { funçóes de cada lobo e hemisférios }\end{array}$ \\
\hline & $\begin{array}{l}\text { Sintese } \\
\text { Montagem de um painel coletivo }\end{array}$ \\
\hline \multirow{3}{*}{$\begin{array}{l}\text { II HEMISFÉRIOS E LOBOS CEREBRAIS- } \\
\text { Características de cada lobo e hemisfério } \\
\text { cerebral. } \\
\text { Temática: O que tenho na cabeça }\end{array}$} & $\begin{array}{l}\text { Sincrese } \\
\text { Jogo dos Hemisférios } \\
\text { Sorteio de Habilidades e competências } \\
\text { predominantes }\end{array}$ \\
\hline & $\begin{array}{l}\text { Análise } \\
\text { Estudo de material impresso sobre algumas } \\
\text { habilidades e competências } \\
\text { Jogos lúdicos com desafios }\end{array}$ \\
\hline & $\begin{array}{l}\text { Sintese } \\
\text { Cruzando ideias } \\
\text { Resumo oral } \\
\text { Resolução de cruzadinha em grupos }\end{array}$ \\
\hline
\end{tabular}

O envolvimento dos alunos incluídos perante a aplicação das estratégias pedagógicas foi analisado em cinco categorias: estética, emoçôes, autonomia, inclusão e Neuroeducação, respeitando diferentes ritmos, capacidades, condiçóes neurofisiológicas. No Quadro 1, apresentamos a síntese dessa análise, enfocando aspectos ligados à acessibilidade pedagógica e à Neurociência. 
Quadro 1-Estratégias e categorias

\begin{tabular}{|c|c|}
\hline Categorias & Estratégias \\
\hline \multirow{5}{*}{ Estética } & $\begin{array}{l}\text { I. A aluna X ao ver a foto de uma criança com Síndrome } \\
\text { de Down aponta dizendo "EU, É EU". A reaçáo denotou } \\
\text { envolvimento, atenção, autoidentificação; seguida da } \\
\text { importância de conhecer melhor as pessoas. Os alunos } \\
\text { incluídos, por apresentarem linguagem limitada com } \\
\text { palavras simples, foram motivados e participaram } \\
\text { oralmente. }\end{array}$ \\
\hline & $\begin{array}{l}\text { II. Evidenciamos curiosidade e motivação; aproximação } \\
\text { entre os participantes e familiarizaçáo com o assunto a } \\
\text { partir das ilustraçóes e conceituaçóes estudadas e aplicadas } \\
\text { ao seu "eu" e seu contexto. Os alunos incluídos puderam } \\
\text { se expressar de diferentes formas: corporal, escrita, oral; } \\
\text { interagir e integrar-se com objetos e com os outros. }\end{array}$ \\
\hline & $\begin{array}{l}\text { III. A partir de situaçóes concretas, com diferentes tipos } \\
\text { de linguagens: musical, artística, corporal, entre outras, } \\
\text { conseguimos que os alunos incluídos se expressassem, } \\
\text { coadunando com as ideias de Tokuhama-Espinosa ( } 2008 \\
\text { apud Zaro et al., 2010) de que o aprendizado é baseado } \\
\text { em parte na habilidade do cérebro de detectar padróes e } \\
\text { fazer aproximaçóes para aprender. }\end{array}$ \\
\hline & $\begin{array}{l}\text { IV. Na dinâmica Memória e Partilha, os alunos incluídos } \\
\text { sentiram dificuldade por estarem acostumados a } \\
\text { reproduzirem discursos, não refletir sobre si; mas foi } \\
\text { possível aproximá-los aos outros, conhecê-los melhor } \\
\text { para entendê-los e buscar formas de auxílio, valorizaçáo } \\
\text { e compreensão. }\end{array}$ \\
\hline & $\begin{array}{l}\text { V. Há conexáo do exterior com o interior - nosso EU, pois } \\
\text { em alguns momentos os alunos incluídos tiveram funçôes } \\
\text { corporais, orais e artísticas estimuladas. Essa referência } \\
\text { a algo pessoal, que traz para o concreto suas percepçôes } \\
\text { por meio das diferentes expressóes, mobilizando- } \\
\text { os e possibilitou se perceberem, conhecerem-se; } \\
\text { resultando em momentos de surpresa por parte deles. } \\
\text { A contextualizaçáo das atividades permitiu sentir suas } \\
\text { habilidades e competências para além do corpo físico, ou } \\
\text { seja, interiormente. }\end{array}$ \\
\hline
\end{tabular}


I. No filme Divertida Mente, os alunos comentaram oralmente sobre suas angústias ou concordância com relação às atitudes de todos os personagens, e os incluídos, devido suas limitações na escrita, representaram por imagens sua percepção. A aluna $\mathrm{X}$ realizou uma projeção abstrata, utilizando as cores das emoçôes; o aluno Y fez o desenho do personagem Raiva, pediu a capa do CD para desenhar e conseguiu fazer uma imagem muito parecida, o que contraria a ideia inicial disposta no parecer da profissional do AEE, que registra que o aluno "apresenta dificuldade em desenhar e pintar".

II. Experimentaçóes com material concreto conferiram uma explosão de sensaçóes, o contato e a vivência de seus sentidos fez com que compreendessem a partir de seu corpo a função de cada sentido. O reconhecimento dos sentidos e suas funçôes é uma limitação/dificuldade dos alunos incluídos, mesmo com a utilização de material concreto não Emoçâo apresentaram familiaridade e contextualização ao que é estudado.

III. Dentre algumas atividades em que os alunos incluídos tiveram sua participaçấo destacada foi nas encenaçóes dos livros da coleção Memórias de um Neurônio Lembrador, quando se envolveram bastante, sendo chamados por seus colegas a realizar atividades de expressão artística (na composiçáo de cenários), oralmente (dramatizaçóes/encenaçóes), o que possibilitou a interação, integraçáo e comunicaçáo entre esses alunos. Dawson e Guare (2010 apud Russo, 2015) fazem referência a isso quando destacam como funçôes executivas: organização, priorização, manejo de tempo, atençáo sustentada, inibição e persistência em direção ao objetivo e regulação emocional

IV. Observamos a participação dos alunos incluídos nos jogos da memória, que quando precisaram escolher as peças do jogo, além de exercitarem a memória, manifestaram controle inibitório e regulaçáo de emoçōes nas tentativas, erros e acertos, sendo apoiados pelo grupo, comportando-se adequadamente, além disso houve mobilização e regulação de emoçôes e açôes; o que evidenciou mobilização de funçôes executivas de autorregulação, que contribui também para inteligência emocional, segundo Goleman (2012). 


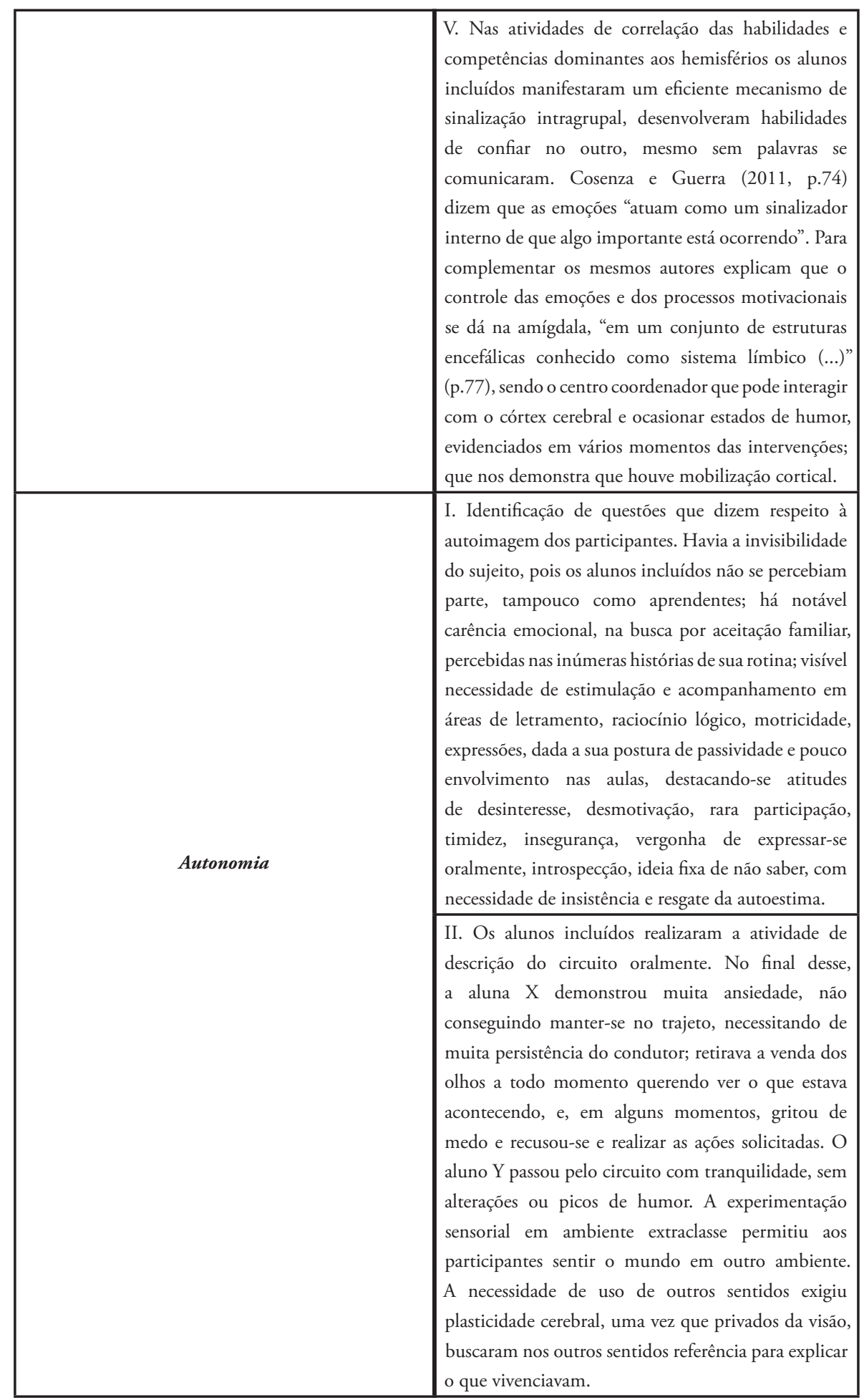


III. No NeuroQuiz evidenciamos algumas atitudes como: liderança, discussão de açóes, tomada de decisão, senso crítico e confronto de conhecimentos e opiniōes. Aqui destacamos as funçóes executivas como funçōes corticais superiores associadas ao lobo frontal, conforme indicam Moss e Killiany apud Russo (2015). Os alunos incluídos desempenharam funçōes executivas, criando coletivamente estratégias para elaboração das questôes que seriam utilizadas no jogo, ainda que na maioria do tempo observando e pouco sugerindo, evidenciaram integração, organização de caminhos para atingir um objetivo; o que, segundo Dawson e Guare (2010) apud Russo (2015), corresponde às habilidades de persistência em direção a um objetivo e regulação emocional (que observamos durante o jogo

IV. Os alunos incluídos nos fizeram observar as duas vertentes da flexibilizaçăo curricular, uma diz respeito ao processo de educação inclusiva, pensada a partir dos grupos de alunos; a outra considera que o processo de inclusão deve ocorrer a partir de adequaçōes curriculares dentro do contexto grupal, embora ainda tenhamos a ideia de olhar para "determinado aluno", a visão muda observando-se a diversidade desse. (BRASIL, 2005 apud GARCIA, 2007). Nas atividades sobre memória, especialmente nos Registros Imagéticos, evidenciamos as diferenças e necessidade de respeito aos diferentes ritmos dos alunos, pois cada um expressou diferentes interpretaçôes sobre uma mesma imagem.

V. Nos desafios os alunos incluídos foram estimulados em sua participação, senso crítico, autonomia, opinião, decisăo, independência de ideias, e, em alguns momentos, enfrentaram o erro, bem como as reaçóes negativas de seus colegas. Percebemos que esses alunos são bastante flexíveis para aceitar os erros, motivando-se para a continuidade das tarefas muito mais fácil e rapidamente que outros colegas. 


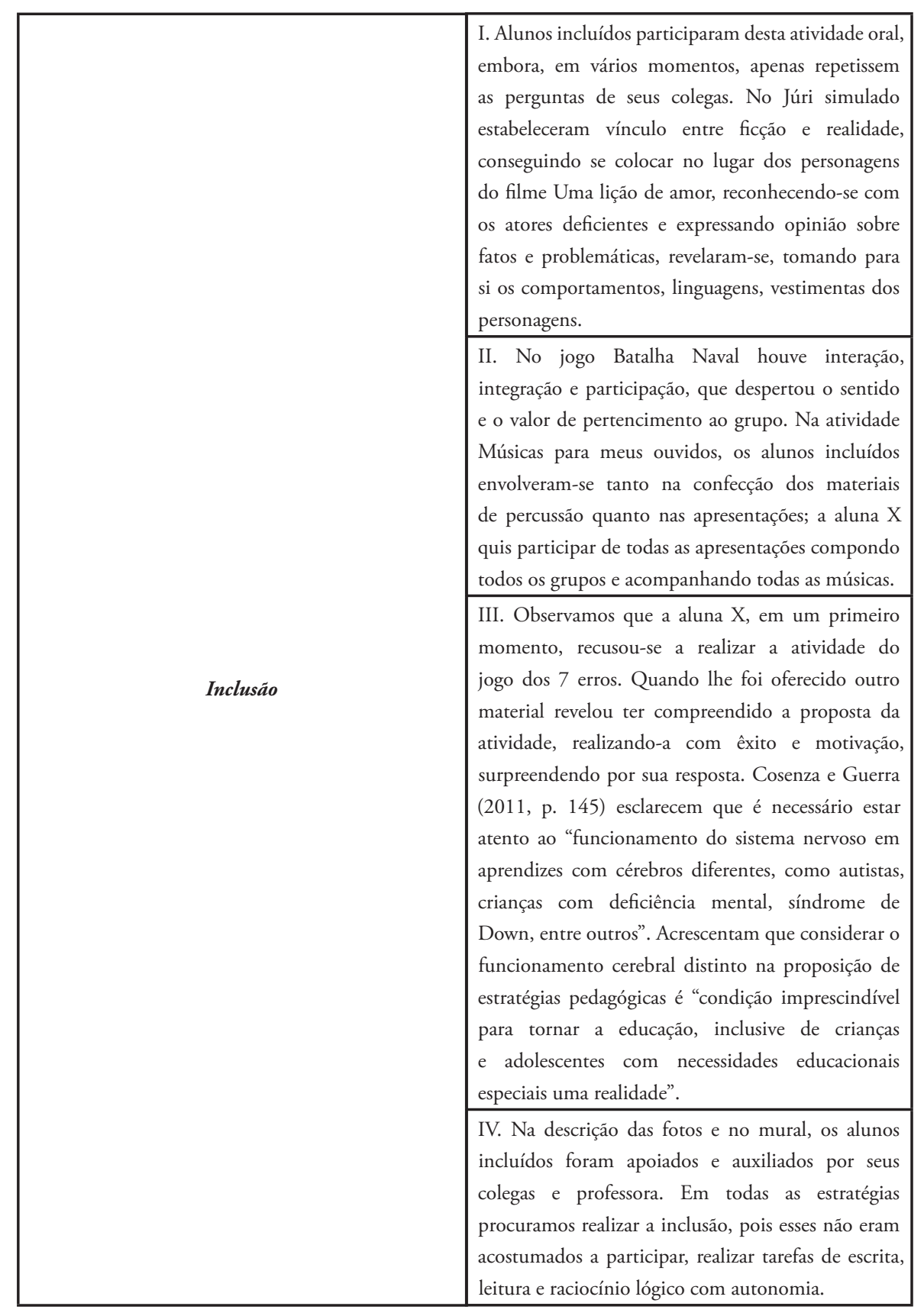




\begin{tabular}{|c|c|}
\hline & $\begin{array}{l}\text { V. Cosenza e Guerra (2011) expressam que a } \\
\text { "plasticidade no fazer e no desfazer as associaçōes } \\
\text { existentes entre as células nervosas é a base da } \\
\text { aprendizagem e permanece, felizmente, ao longo } \\
\text { de toda a vida". Atividades de experimentação, } \\
\text { montagem e desafio despertaram a atençáo e } \\
\text { promoveram relaçóes com sua realidade dos alunos } \\
\text { incluídos, motivados pelas atividades concretas, } \\
\text { jogos e desafios, aceitando auxílio, buscando realizar } \\
\text { as atividades e enfrentando suas limitaçōes. }\end{array}$ \\
\hline \multirow{3}{*}{ Neuroeducaçäo } & $\begin{array}{l}\text { I. A Neurociência possibilita a compreensão } \\
\text { da importância de estimularmos os diferentes } \\
\text { sentidos dos alunos incluídos (auditivo, visual, tátil, } \\
\text { gustativo, olfativo) e, desse modo, seus diferentes } \\
\text { receptores. Dos princípios da Neuroeducação, } \\
\text { conforme Tokuhama-Espinosa ( } 2008 \text { apud ZARO } \\
\text { et al., 2010), destacamos que: os estudantes } \\
\text { aprendem melhor quando são altamente motivados } \\
\text { do que quando náo têm motivação; o tom de voz } \\
\text { de outras pessoas é rapidamente julgado no cérebro } \\
\text { como ameaçador ou náo-ameaçador; o feedback } \\
\text { é importante para o aprendizado e o humor pode } \\
\text { potencializar as oportunidades de aprendizado. }\end{array}$ \\
\hline & $\begin{array}{l}\text { II. Em todas as atividades, os alunos incluídos foram } \\
\text { motivados e o tom de voz do condutor no Circuito } \\
\text { Sensorial foi importante, assim como a realização } \\
\text { das sínteses do conhecimento, procuramos } \\
\text { estimular a modificação e desequilibração de humor } \\
\text { em inúmeros momentos, observando princípios } \\
\text { importantes da Neuroeducaçáo, destacadas por } \\
\text { Tokuhama-Espinosa (2008 apud Zaro et al., 2010). }\end{array}$ \\
\hline & $\begin{array}{l}\text { III. Na Caça ao Tesouro utilizamos exploração do } \\
\text { ambiente, desafio coletivo e de organizaçáo espacial, } \\
\text { e percebemos, que o cérebro é social e cresce na } \\
\text { interaçáo e na reflexáo pessoal. Os alunos incluídos } \\
\text { sentiram-se um pouco deslocados, retirando-se, às } \\
\text { vezes, do grupo, sentindo-se perdidos e buscando } \\
\text { até mesmo outros grupos com colegas aos quais } \\
\text { estâo mais acostumados ou com a professora. }\end{array}$ \\
\hline
\end{tabular}




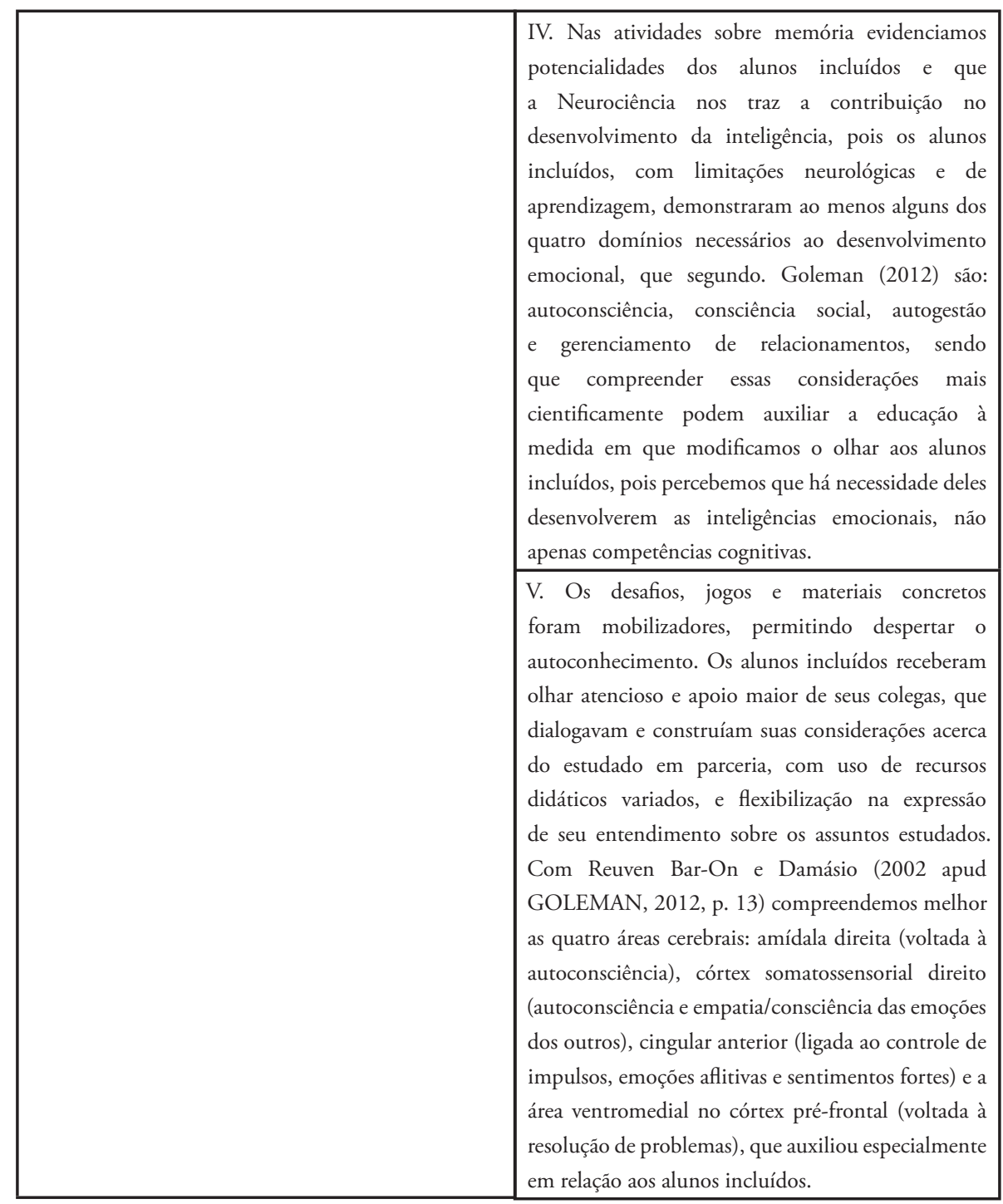

Analisando, em geral, percebemos que inúmeros desafios se fizeram presentes nas estratégias, com ludicidade nos jogos coletivos, exigindo participação, senso crítico, autonomia, opinião, decisão, independência de ideias; em alguns momentos foi necessário enfrentar o erro, bem como as reaçôes negativas dos colegas e continuar com a tarefa proposta. Excelente momento para perceber que os alunos incluídos são bastante flexíveis, demorando menos tempo para aceitar os erros e motivando-se para a continuidade das tarefas com mais flexibilidade que outros colegas. 
As intervençóes renderam resultados surpreendentes, dentre os quais destacamos: a ampliação de visão do docente em sua análise frente ao processo ensino -aprendizagem, a relevância e a importância de se organizar um trabalho para todos, a comprovaçáo de que planejamentos flexibilizados podem atender a um grupo maior de alunos em sala de aula e assim atender ao máximo a diversidade, reconhecer e promover o desenvolvimento de habilidades diferenciadas em todos os alunos é tarefa docente, além de serem destacadas muitas atividades que deram certo e que tiveram eficácia especialmente no fator comportamental dos alunos incluídos, mas não somente deles como evidenciamos mudança em todo o grupo participante.

\section{(In)Conclusão}

O diagnóstico inicial da turma revelou necessário mudar a realidade na turma estudada para torná-la inclusiva. Infelizmente estávamos inseridos em um contexto com problemáticas, como: presença de ensino tradicional; não compreensão da dinâmica e das normativas de inclusão; pouco tempo para planejamento diversificado, fundamentado e interessante incluindo flexibilizaçóes aos alunos com deficiência; falta de material concreto para promoção da aprendizagem prazerosa; pouca clareza de referencial teórico-metodológico, entre outras.

Assim, as estratégias de ensinagem com temas geradores foram possibilidades para flexibilização curricular a educandos incluídos. As temáticas norteadoras possibilitaram mais significado e contextualização ao apreendido. Os questionamentos orais, as atividades artísticas, a expressão corporal, com espaço-tempos previstos pela escola (educação física, informática, pátio, eventos em datas comemorativas), as atividades em grupo, com interação e integração, além dos desafios frente às diferenças de ideias e os momentos de discussão dos problemas na busca por mudanças, foram importantes na prática desenvolvida. Ainda é desafio a atualização da formação docente em relação a estudos sobre inclusão e meios de modificar sua prática atendendo aos desafios, com replanejamento da prática, organização de estratégias metodológicas inovadoras com suporte na Neurociência e observância à diversidade.

Acreditamos que intervençóes inovadoras com práticas inclusivas, flexibilidade curricular, entendimento do funcionamento do cérebro e da plasticidade cerebral resultam em ensinagem com melhor qualidade. Esta pesquisa, portanto, traz o estreitamento das relaçóes entre essas duas grandes áreas que formam a Neuroeducação.

Frente a tudo isso, destacamos a relação íntima do planejamento de estratégias de intervenção com suporte na Neurociência em prol da acessibilidade pedagógica, justificados pelos objetivos atingidos e pelos resultados inicialmente comportamentais e emocionais que poderão evoluir para cognitivos dada a grande estimulação e reorganização proposta aos alunos incluídos. Mesmo que o resultado dessa prática se dê a longo prazo, a esperança pela construção de uma escola mais inclusiva continuará presente em nossas mentes, coraçôes e açóes diárias como compromisso social. 


\section{Referências}

ALMEIDA, L. R. Diário de Itinerância: recursos para a formação e avaliaçấo de estudantes universitários. Est. Aval. Educ. São Paulo, v.23, n.51, p.250-269, jan/abr.2012.

BAPTISTA, C. R. (Org.). Escolarização e deficiência: configuraçôes nas políticas de inclusão escolar. São Paulo: Marquezini \& Manzini: ABPEE, 2015.

BOSMANS, P. Os cinco sentidos: os sentidos explicados para crianças de 5 a 9 anos. Peter Mosmans; ilustraçôes: Johan Verheyen; Tradução Valerie Dominique G.S. C. Blumenau: EKO, 1997.

COSENZA, R. M., GUERRA, L.B. Neurociência e Educação: como o cérebro aprende. Porto Alegre, RS: Artmed, 2011.

GARCIA, R. M. C. Os conceitos de flexibilidade curricular nas políticas públicas de inclusão educacional. In: JESUS, D. M. (Org.). Inclusão, práticas pedagógicas e trajetórias de pesquisa. Porto Alegre: Mediação, 2007.

GOLEMAN, D. O cérebro e a inteligência emocional: novas perspectivas. Tradução: Carlos Leite da Silva. Rio de Janeiro: Objetiva, 2012.

RUSSO, R. M. T. Neuropsicopedagogia clínica: introdução, conceitos, teoria e prática. Curitiba: Juruá, 2015.

THIOLLENT, M. J. M.; COLETTE, M. M. Pesquisa-ação, formação de professores e diversidade. Acta Scientiarum. Human and Social Sciences. Maringá, v. 36, n. 2, p. 207-216, July-Dec., 2014. Disponível em http:// www.uem.br/acta

THIOLLENT, M. Metodologia da pesquisa-açáo. 18.ed. São Paulo: Cortez, 2011.

TOKUHAMA-ESPINOSA, T. N. The scientifically substantiated art of teaching: a study in the development of standards in the new academic field of neuroeducation (mind, brain, and education science). Tese de Doutorado, Programa de Pós-Graduação em Educação, Capella University, Mineápolis, Minesota, 2008.

VASCONCELLOS, C. dos S. Construçáo do conhecimento em sala de aula. 18. ed. São Paulo: Libertad, 2005.

VEIGA, I. Pontos de reflexão sobre as licenciaturas interdisciplinares. Brasília, 2015. (Notas da autora).

ZARO, M.A.; ROSAT, R.M.; MEIRELES, L.O.R.; SPINDOLA, M.; AZEVEDO, M.P. de; BONINI-ROCHA, A.C.; TIMM, M.I. Emergência da Neuroeducação: a hora e a vez da neurociência para agregar valor à pesquisa educacional. Ciências \& Cogniçáo. Porto Alegre: UFRGS, v.15, n.2, p. 199-210. 2010.Disponível em <http://www.cienciasecognicao.org> Acesso em: 21 jul. 2016.

\section{Notas}

${ }^{1}$ Grifos nossos.

\section{Correspondência}

Luciane Grecilo da Silva - Unipampa.BR 472 - Km 585. CEP:97501-970. Uruguaiana, Rio Grande de Sul, Brasil.

E-mail: lugrecilo@hotmail.com - profelena@gmail.com

Recebido em 1 de setembro de 2017

Aprovado em 26 de fevereiro de 2018

\section{(c) (i) (8)}

This work is licensed under a Creative Commons Attribution-NonCommercial 4.0 International (CC BY-NC 4.0) 